\title{
DISSENT
}

\section{Public health and traffic safety: a collaborative success}

\author{
A M Dellinger, C M Branche, B H Jones
}

In our original article, we showed graphically that deaths/100 million vehicle miles traveled (VMT) in the United States have been steadily decreasing since $1925 .{ }^{1}$ We also showed motor vehicle related death rates/100 000 population decreased from 1966 to 1999 . This decrease in deaths/100 000 population illustrated the impressive declines that resulted from aggressive traffic safety and public health measures. ${ }^{1}$ Richter et al have taken issue with our assertion that motor vehicle safety represents a public health success launched in the 1960s. What we did not show in our original article was that before 1966, despite continuous decreases in the traffic safety indicator (deaths (D)/100 million VMT), the actual number of motor vehicle deaths increased $242 \%$ during the period 1925 through 1966 (from 21900 to 53 041, respectively), and the death rate/100 000 population increased $42 \%$ (from 19.1 in 1925 to 27.1 in 1966). The measure used to set public health priorities and to compare health problemsdeaths/100 000 population-increased both before and after World War II. From 1960 to 1966, deaths/100 000 population increased $28 \%$, prompting federal legislation to curb the problem. ${ }^{2}$

Later, in response to a letter to the editor, we supported the observation that the Highway
Safety Act of 1966 and related initiatives marked a milestone in motor vehicle safety, by showing deaths and death rates/100 000 population before and after enactment. ${ }^{34}$ We include a similar figure here to show the increase in both deaths and death rates from 1925 to 1969 , followed by dramatic declines after the creation of the National Highway Traffic Safety Administration in the United States Department of Transportation in 1970 (see fig 1). This began a 30 year downward trend in mortality, the longest in United States history, which occurred despite increased numbers of vehicles, miles traveled, and a growing population. This decline did not occur by happenstance; motor vehicle injury prevention became a major transportation and public health priority.

As the end of the century approached, the Centers for Disease Control assessed key public health achievements for the 20th centurythose significantly affecting the nation's health. The declines in motor vehicle related mortality rates, especially over the last third of the century, clearly had a marked impact on public health. In our original article, we recognized the contributions of multiple government and community based agencies and organizations. ${ }^{1}$ Motor vehicle safety programs succeed
Division of

Unintentional Injury

Prevention, National Center for Injury Prevention and

Control, Centers for Disease Control and Prevention

A $M$ Dellinger

C M Branche

B H Jones

Correspondence to: Dr Christine Branche, Division of Unintentional Injury Prevention, National Center for Injury Prevention and Control, 4770 Buford Highway NE, Mailstop

K-63, Atlanta, GA 30341-3724, USA crb3@cdc.gov

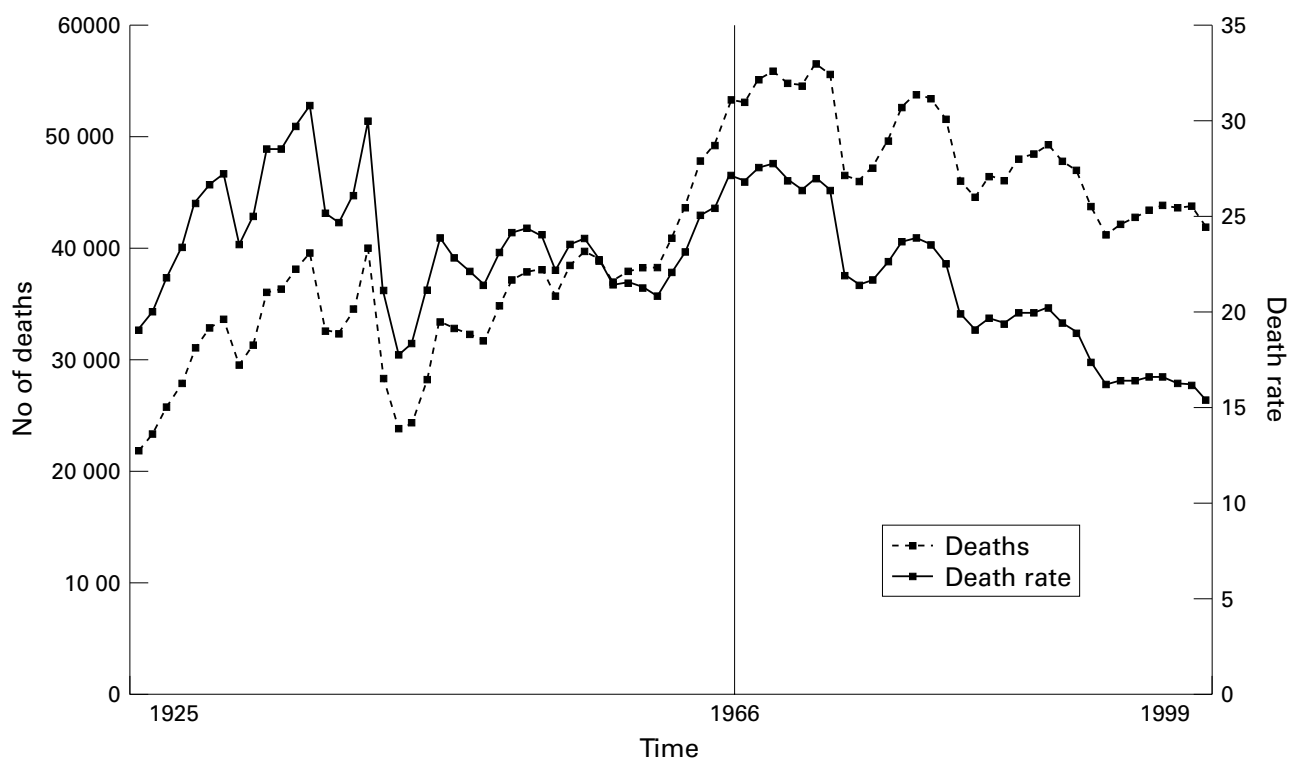

Figure 1 Number of motor vehicle related deaths and death rates/100 000 population, United States 1925-99. 
through the efforts of federal and state governments, academic institutions, community based organizations, and industry working together to improve the public's health.

Richter et al: (1) take issue with the assertion that public health has contributed to the decline in deaths due to motor vehicle crashes; (2) they question the use of D/VMT as a valid measure of the improvement in traffic safety in the United States; and (3) they argue that the primary culprit in motor vehicle related deaths is speed.

Richter et al suggest that because recent declines have been more gradual than in the past, and not monotonic, motor vehicle safety is a public health failure. However, motor vehicle injury is a problem that requires a long term view. It is apparent that brief short term increases in risk are generally followed by declines, with the net result being a steady long term decline. This includes the period from 1966 to present, when the United States government, agencies, and private organizations intensified their safety efforts.

Richter et al argue against the use of the traffic safety measure, D/VMT. However, this is just one of many possible measures, although it is a standard for the traffic safety community. Measures such as deaths/10 000 motor vehicles, deaths/100 000 population (a standard public health measure), and absolute numbers of deaths alone, also have been falling in the United States, while the numbers of drivers and the number of miles traveled have increased. ${ }^{4}$ Each measure has its advantages and disadvantages for use. During most of the last century, D/VMT declined, and over the last 30 years there has been remarkable consistency across all measures, each showing decreasing risk of death over time.

Richter et al claim that the primary failure of traffic safety has been the control of speed. They assert that motor vehicle case fatality rates can be used to estimate the effects of speed on motor vehicle fatality trends. While we agree that speed is an important contributor to crashes and the case fatality rate, their argument has several shortcomings. We suggest the following:

(1) The definition of the case fatality rate needs refinement. We suggest it be defined as the number of deaths/1000 injuries (not as the number of deaths/1000 vehicles).

(2) Non-occupants should be excluded from the calculations (Richter et al use total deaths which include occupants (drivers and passengers), pedestrians, and bicyclists for whom case fatality rates differ), or use separate calculations for person-types that have different case fatality rates.

(3) Adjust estimates of the effect of speed for other factors that affect the case fatality rate in addition to speed. ${ }^{5}$ For example, type of crash (for example, rollover crashes have the highest case fatality), restraint use (including airbags), type of vehicle or vehicle weight, and age of crash victims.

Richter et al contend we should look at the numbers of deaths, not the rates, and our objective should be to reduce absolute numbers. Simply trading absolute numbers of motor vehicle related deaths would not be good science. However, we agree that 40000 annual deaths due to motor vehicle crashes are not an acceptable outcome from either the public health or traffic safety perspectives. While speed represents a clear risk factor for motor vehicle fatalities, many other factors also influence risk, for example, disregard for other traffic regulations, alcohol impaired driving, frailty among older adults, failure to use effective countermeasures such as seat belts and child safety seats, and others. Motor vehicle safety has improved immensely over the last 40 years (see fig 1). Multiple professions and organizations have contributed and will continue to contribute to that success. Future improvements will require their sustained, collaborative efforts.

1 Centers for Disease Control. Achievements in public health, 1990-1999. Motor vehicle safety: a 20th century public health achievement. MMWR Morb Mortal Wkly Rep 1999;48(18):369-74

2 Highway Safety Act of 1966 Pub L No 89-564 codified as 23 USC 402 et seq and Motor Vehicle Safety Act, Pub L No 89-563 enacted 9 September 1966.

3 Jones B, Sleet D, Dellinger A, et al. Reductions in motor vehicle-related injuries and deaths (letter). $7 A M A$ 1999; 282:2210-11.

4 National Safety Council. Accident facts. Itasca, IL: National Safety Council, 1998.

5 Cerrelli EC. Fatal crash involvements-what are the odds? Research note. Washington, DC: National Highway Traffic Safety Administration, US Department of Transportation, July 1997. 